\title{
Embracing change: the era for pediatric ERAS is here
}

\author{
Mary E. Brindle ${ }^{1}$ (D) Kurt Heiss ${ }^{2} \cdot$ Michael J. Scott $^{3,4} \cdot$ C. Anthony Herndon ${ }^{5} \cdot$ Olle Ljungqvist $^{6} \cdot$ Martin A. Koyle $^{7} \cdot$ on $^{-}$ \\ behalf Pediatric ERAS (Enhanced Recovery After Surgery) Society
}

Accepted: 1 April 2019 / Published online: 25 April 2019

(c) The Author(s) 2019

\begin{abstract}
The concept of Enhanced Recovery After Surgery (ERAS) has increasingly been embraced by our adult surgical colleagues, but has been slow to crossover to pediatric surgical subspecialties. ERAS ${ }^{\circledR}$ improves outcomes through multiple, incremental steps that act synergistically throughout the entire surgical journey. In practice, ERAS ${ }^{\circledR}$ is a strategy of perioperative management that is defined by strong implementation and ongoing adherence to a patient-focused, multidisciplinary, and multimodal approach. There are increasing numbers of surgical teams exploring ERAS ${ }^{\circledR}$ in children and there is mounting evidence that this approach may improve surgical care for children across the globe. The first World Congress in Pediatric ERAS $^{\circledR}$ in 2018 has set the stage for a new era in pediatric surgical safety.
\end{abstract}

Keywords ERAS $\cdot$ Enhanced recovery after surgery $\cdot$ Care pathways $\cdot$ Quality and safety $\cdot$ Outcomes

The concept of Enhanced Recovery After Surgery (ERAS) has increasingly been embraced by our adult surgical colleagues. To date, however, the concepts of ERAS have been slow to crossover to pediatric surgical subspecialties.

On November 30th, 2018 in Richmond, Virginia, the first World Congress for Pediatric Enhanced Recovery After Surgery $\left(\right.$ ERAS $^{\circledR}$ ) was held, bringing together experts in standardized perioperative pediatric care from across the globe.

Mary E. Brindle

MaryEBrindle@gmail.com

1 Department of Surgery, Cumming School of Medicine, Alberta Children's Hospital, University of Calgary, 28 Oki Drive, Calgary, AB T3B6A8, Canada

2 Department of Surgery, Emory University, Atlanta, GA, USA

3 Department of Anesthesiology, Virginia Commonwealth University Health System, Richmond, VA, USA

4 Department of Anesthesiology and Critical Care Medicine, Perelman School of Medicine, University of Pennsylvania, Philadelphia, USA

5 Department of Surgery, Virginia Commonwealth University Health System, Richmond, VA, USA

6 Faculty of Medicine and Health, School of Health and Medical Sciences, Department of Surgery, Örebro University, Örebro, Sweden

7 Department of Surgery, University of Toronto, Toronto, ON, Canada
The aim of this meeting was to set the stage for a revolution in pediatric surgical care, by forming a working group for ERAS $^{\circledR}$ pediatric surgery within the ERAS ${ }^{\circledR}$ Society (www. erassociety.org).

ERAS $^{\circledR}$ follows a holistic approach to the treatment of surgical patients. The origins of ERAS ${ }^{\circledR}$ are rooted in the concept that patient outcomes can be improved through the modulation of the physiologic response to surgical stress [1]. Early on, ERAS ${ }^{\circledR}$ pioneers recognized that this approach required consideration of a multitude of factors simultaneously as well as involvement of stakeholders in the patient experience to effect change in outcomes. Rather than focusing on a single intervention, ERAS ${ }^{\circledR}$ improves outcomes through multiple, incremental steps that act synergistically throughout the entire surgical journey (preoperative, intra/ perioperative, and post-operative phases of care). In practice, ERAS $^{\circledR}$ is a strategy of perioperative management that is defined by strong implementation and ongoing adherence to a patient-focused, multi-disciplinary, and multimodal approach. This requires a team-based culture that includes not only those who directly care for a patient, but also the patients themselves, who are active participants in the process, not simply passive recipient of care.

The impact of ERAS ${ }^{\circledR}$ on patient outcomes has been considerable. Guidelines from the ERAS ${ }^{\circledR}$ Society were first established in adult colorectal surgery and have since expanded into multiple areas of surgery including 
gynecology, orthopedic surgery, and cardiac surgery [2]. Some of the earliest benefits observed with ERAS ${ }^{\circledR}$ were shortened length of stay (LOS) and reduced cost through early mobilization, early feeding and early discharge [3]. Further development and study of these guidelines has shown improved outcomes in mortality and multiple measures of morbidity as well as improved patient and care-giver satisfaction [4] and cost savings [5].

For an approach that has been transformative in surgical care for adults, the impact ERAS ${ }^{\circledR}$ has made in pediatric surgery has been surprisingly limited. A literature review by Shinnick et al. in 2016 demonstrated that there were, at that time, only a small number of studies examining the impact of ERAS ${ }^{\circledR}$ protocols in children. Despite adoption of only a few ERAS ${ }^{\circledR}$ elements, these studies showed its benefits in reducing length of stay and decreasing use of narcotics [6].

Determining which outcomes are most important for pediatric surgical patients and which are most amenable to study require careful consideration when creating ERAS ${ }^{\circledR}$ Society guidelines for children. All recommendations within ERAS $^{\circledR}$ guidelines directly or indirectly address key, measurable outcomes. Most pediatric surgical patients are healthy with few comorbidities. Mortality is difficult to study in this population when perioperative death is rare; morbidity is easier to measure. Infectious complications are some of the most common and important adverse events effecting these patients [7]. Infections are captured in many of the quality improvement databases (i.e., the National Surgical Quality Improvement Program, NSQIP), although a common nomenclature is required when comparing outcomes across countries and databases. LOS is also easily measured, and can be improved upon relatively quickly. However, LOS is a complicated outcome, impacted by multiple different contributors including comorbidities, social factors, and care pathways. Additional outcomes that are easily overlooked, but have great importance include those related to parent, patient, and team-member satisfaction. These outcomes are important in their own right. In addition, buy-into a care pathway allows for the optimal introduction and acceptance of best practices and allows for integration of new evidencebased care practices, as they evolve [8].

Without a doubt, implementing ERAS ${ }^{\circledR}$ requires a shift in culture that is based on collaboration, not traditional silos of care. Resistance to adopting ERAS ${ }^{\circledR}$ from pediatric surgeons and anesthesiologists often hinges on the perceived impact of ERAS $^{\circledR}$ on operating room efficiency and the uncertain merit of individual elements for children such as fasting guidelines $[9,10]$. There is also a widespread belief that the value of guidelines, checklists, and other tools is limited in a population that, on the whole, is healthy and has a low risk of adverse events [11]. Many clinicians believe that evidencebased practices are already widely adopted, that they are "already doing ERAS ${ }^{\circledR}$ protocols", and that many guidelines are redundant [12]. And yet, best practices are not always followed, and medical errors and adverse events do occur in the pediatric population at a rate that is higher than it should be [7, 13-15]. The rates of adverse events in the population of hospitalized Canadian children have been measured at close to $10 \%$ with the highest rates seen in surgical patients [16]. Neonates are at particularly high risk with rates of surgical site infections reported as high as $13.5 \%[17,18]$. The morbidity associated with these infections is reflected in a length of stay for these infants that is three times longer than the stay of their uninfected counterparts [17].

Adolescents, children, and infants all have unique issues that must be addressed in surgical care pathways. Physiologically, neonates encounter considerable challenges when exposed to operative stress; their immune systems are immature, their circulation is transitioning from the intrauterine to the extrauterine state, their thermoregulation is depressed and their respiratory systems may be underdeveloped, among numerous other physiologic challenges [19-21]. In addition, the energy requirements for growth and neurodevelopment must compete with those of healing, making nutritional management complex [22, 23]. Physiologic concerns impact children at all the stages of development, and change throughout childhood and adolescence.

Pediatric surgical care is as complex sociologically, as it is physiologically, with evolving patient participation and a key role assumed by parents as advocates and decision makers. Parents are often very supportive of guidelines and practices that include parent involvement [24]. However, ERAS ${ }^{\circledR}$ guidelines put additional pressures on parents. Increased protocol complexity before and after surgery that increasingly shifts care out of hospital can become a challenging parent and patient responsibility [24]. Older children and adolescents require a nuanced approach to communication and decisionmaking. As children age and mature, they are increasingly able to understand and participate in care decisions and, eventually, assume autonomous decision-making [25]. The evolving needs of children and their families in the implementation of care pathways must be carefully considered [25].

There is good reason to believe that children will benefit from ERAS ${ }^{\circledR}$, as has been shown in the few studies that have explored this topic [6]. There is also good reason to believe that some aspects of pediatric ERAS ${ }^{\circledR}$ guidelines may be different from those of adults, both in terms of content and the mechanism through which these guidelines are used [21].

ERAS $^{\circledR}$ or ERAS ${ }^{\circledR}$-like guidelines have been developed within a number of pediatric specialties and many traditional ERAS elements have been adopted from adult guidelines especially for adolescents. The majority of these guidelines have been created specifically for single sites [26, 27]. Following a multi-disciplinary American Academy of Pediatrics symposium in 2017, a multi-center working group was organized by Raval et al. and has taken a broader view, 
created a colorectal guideline designed for staggered adoption at 18 sites across the United States [12]. To create this guideline, an expert group of pediatric surgeons assessed existing colorectal ERAS ${ }^{\circledR}$ Society guideline elements and performed an evidence-review of controversial practice. This group eventually agreed that 14 out of 21 elements should be adopted for an adolescent colorectal care pathway [12]. Although the resulting ERAS ${ }^{\circledR}$ guideline was remarkably similar to existing adult ERAS ${ }^{\circledR}$ Society guidelines, the implementation strategy identified some key differences required to make the guideline work for adolescent patients. The focus on shared parent and patient decisionmaking resulted in a protocol that would be embraced by a patient population that increasingly assumes responsibility for its own care [28]. Similar approaches to adaption of adult ERAS $^{\circledR}$ protocols for use in pediatric patients have been undertaken with considerable success for scoliosis surgery and urogenital reconstruction, and many others [27, 29, 30].

Neonatal ERAS ${ }^{\circledR}$, however, has required a different approach to guideline creation due to the dramatic differences in physiology and unique qualities of the care teams involved. Gibb et al. developed a protocol for ERAS ${ }^{\circledR}$ guideline creation that has resulted in a neonatal ERAS guideline for intestinal resection surgery [21]. Using the ERAS ${ }^{\circledR}$ Society framework, new elements were developed addressing neonatal needs in the preoperative, intraoperative, and post-operative periods. This process resulted in a guideline that in some ways looks familiar, but in other ways, is dramatically different. The Neonatal ERAS ${ }^{\circledR}$ guideline contains new elements encouraging the early introduction of breast milk, urinary sodium monitoring and mucous fistula feeding for patients with stomas as well as limiting unnecessary antibiotics, and optimizing hemoglobin management, as well as numerous other unique recommendations [21]. The development of this first Neonatal ERAS ${ }^{\circledR}$ guideline opens the door for future care pathways targeting this population.

Through the process of creating ERAS ${ }^{\circledR}$ Society guidelines for children, we recognize how much remains to be learned about optimal pediatric surgical care. There are numerous practices for which the data are sparse or of poor quality (e.g., the duration and timing of perioperative antibiotics, the use of post-operative urinary catheters, and bowel preparation prior to surgery) [21,28]. Extrapolation from adult data can be undertaken for numerous ERAS ${ }^{\circledR}$ elements (e.g., timing of preoperative antibiotics). However, there are other practices for which it is clear that better data are needed to make recommendations for care practices (e.g., which preoperative prep solution is best for neonates), or unique patient populations that may require different approaches (anorectal malformations and motility patients). The lack of high-quality evidence can lead to a lack of buy-in from key stakeholders and rejection of guidelines. The end result is a situation that is characterized by numerous, idiosyncratic, and variable approaches to surgical care. And yet, we have seen time and time again that care pathways can decrease unwanted variability and improve outcomes for both children and adults [2, 31, 32]. Guidelines also help us focus our attention on where there is a need for new evidence.

Several groups across the globe have already taken part in the creation and adoption of guidelines and standards that tackle aspects of pediatric surgical care outside of an ERAS ${ }^{\circledR}$ process. The Euroconsortium and the Canadian Congenital Diaphragmatic Hernia (CDH) Collaborative have both made evidence-based recommendations regarding the care of infants with $\mathrm{CDH}$ ) [33, 34]. Similarly, APSA has created guidelines for pectus carinatum deformities as well as other pediatric surgical conditions [35], and standards for the provision of pediatric surgical care have been published by groups including the Royal College of Surgeons in the United Kingdom [36]. These are just some examples of the world-wide readiness for ERAS ${ }^{\circledR}$. The potential global impact of pediatric ERAS ${ }^{\circledR}$ can extend to address some of the specific concerns encountered in low- and middle-income countries.

At the first ERAS ${ }^{\circledR}$ Society Pediatric World Congress in Richmond, a working group of clinicians and investigators from across the world formed the first Pediatric ERAS ${ }^{\circledR}$ Society Committee, and laid the strategic foundations to guide the development of Pediatric ERAS. There are key areas, where ERAS ${ }^{\circledR}$ protocols have been developed, or could easily be created. Beyond this, the Pediatric ERAS ${ }^{\circledR}$ Society Committee will start to tackle recommendations and principles that hold true across the broad scope of pediatric surgical care. There is incredible potential for ERAS $^{\circledR}$ to improve surgical care for children across the globe. November 30th, 2018 was a first step towards a new era in ERAS $^{\circledR}$ as well a new era for pediatric surgical patients, their families, and the teams that care for them.

Funding There was no funding support provided for this article.

\section{Compliance with ethical standards}

Conflicts of interest None of the authors of this paper have any conflicts of interest. Dr. Olle Ljungqvist is the chair of the ERAS ${ }^{\circledR}$ Society Executive Committee and Dr. Michael J Scott is a board member of the ERAS $^{\circledR}$ Society Executive Committee.

Human and animal rights Although prior studies are referenced, this article does not contain any studies with human participants performed by any of the authors. 
Open Access This article is distributed under the terms of the Creative Commons Attribution 4.0 International License (http://creativeco mmons.org/licenses/by/4.0/), which permits unrestricted use, distribution, and reproduction in any medium, provided you give appropriate credit to the original author(s) and the source, provide a link to the Creative Commons license, and indicate if changes were made.

\section{References}

1. Ljungqvist O, Jonathan E (2012) Rhoads lecture 2011: insulin resistance and enhanced recovery after surgery. JPEN J Parent Enteral Nutr 36(4):389-398

2. Ljungqvist O, Scott M, Fearon KC (2017) Enhanced recovery after surgery: a review. JAMA Surg 152(3):292-298

3. Gustafsson UO, Hausel J, Thorell A et al (2011) Adherence to the enhanced recovery after surgery protocol and outcomes after colorectal cancer surgery. Arch Surg 146(5):571-577

4. Group EC (2015) The impact of enhanced recovery protocol compliance on elective colorectal cancer resection: results from an international registry. Ann Surg 261(6):1153-1159

5. Ljungqvist O, Thanh NX, Nelson G (2017) ERAS-value based surgery. J Surg Oncol 116(5):608-612

6. Shinnick JK, Short HL, Heiss KF, Santore MT, Blakely ML, Raval MV (2016) Enhancing recovery in pediatric surgery: a review of the literature. J Surg Res 202(1):165-176

7. Raval MV, Dillon PW, Bruny JL et al (2011) Pediatric American College of Surgeons National Surgical Quality Improvement Program: feasibility of a novel, prospective assessment of surgical outcomes. J Pediatr Surg 46(1):115-121

8. Simons LE, Logan DE, Chastain L, Cerullo M (2010) Engagement in multidisciplinary interventions for pediatric chronic pain: parental expectations, barriers, and child outcomes. Clin J Pain 26(4):291-299

9. Brunet-Wood K, Simons M, Evasiuk A et al (2016) Surgical fasting guidelines in children: are we putting them into practice? J Pediatr Surg 51(8):1298-1302

10. Crenshaw JT, Winslow EH (2002) Preoperative fasting: old habits die hard. Am J Nurs 102(5):36-44 (quiz 5)

11. Cabana MD, Rand CS, Powe NR et al (1999) Why don't physicians follow clinical practice guidelines? A framework for improvement. Jama 282(15):1458-1465

12. Short HL, Heiss KF, Burch K et al (2017) Implementation of an enhanced recovery protocol in pediatric colorectal surgery. $\mathbf{J}$ Pediatr Surg 53(4):688-692

13. Steinman MA, Fischer MA, Shlipak MG et al (2004) Clinician awareness of adherence to hypertension guidelines. Am J Med 117(10):747-754

14. Segal I, Kang C, Albersheim SG, Skarsgard ED, Lavoie PM (2014) Surgical site infections in infants admitted to the neonatal intensive care unit. J Pediatr Surg 49(3):381-384

15. Brindle ME, Henrich N, Foster A et al (2018) Implementation of surgical debriefing programs in large health systems: an exploratory qualitative analysis. BMC Health Serv Res 18(1):210

16. Matlow AG, Baker GR, Flintoft V et al (2012) Adverse events among children in Canadian hospitals: the Canadian Paediatric Adverse Events Study. CMAJ Can Med Assoc J journal de l'Association medicale canadienne 184(13):E709-E718

17. Woldemicael AY, Bradley S, Pardy C, Richards J, Trerotoli P, Giuliani S. Surgical Site Infection in a Tertiary Neonatal Surgery Centre. Eur J Pediatr Surg 2018

18. Clements KE, Fisher M, Quaye K, O’Donnell R, Whyte C, Horgan MJ (2016) Surgical site infections in the NICU. J Pediatr Surg 51(9):1405-1408
19. Le Compte AJ, Chase JG, Lynn A, Hann CE, Shaw GM, Lin J (2011) Development of blood glucose control for extremely premature infants. Comput Methods Programs Biomed 102(2):181-191

20. Mellon RD, Simone AF, Rappaport BAJA (2007) Analgesia. Use of anesthetic agents in neonates and young children. Anesth Anal 104(3):509-520

21. Gibb ACN, Crosby MA, McDiarmid C et al (2018) Creation of an Enhanced Recovery After Surgery (ERAS) Guideline for neonatal intestinal surgery patients: a knowledge synthesis and consensus generation approach and protocol study. BMJ Open 8(12):e023651

22. Mitting R, Marino L, Macrae D, Shastri N, Meyer R, Pathan N (2015) Nutritional status and clinical outcome in postterm neonates undergoing surgery for congenital heart disease. Pediatr Crit Care Med 16(5):448-452

23. Velazco CS, Zurakowski D, Fullerton BS, Bechard LJ, Jaksic T, Mehta NM (2017) Nutrient delivery in mechanically ventilated surgical patients in the pediatric critical care unit. J Pediatr Surg 52(1):145-148

24. Leeds IL, Boss EF, George JA, Strockbine V, Wick EC, Jelin EB (2016) Preparing enhanced recovery after surgery for implementation in pediatric populations. J Pediatr Surg 51(12):2126-2129

25. Grootens-Wiegers P, Hein IM, van den Broek JM, de Vries MC (2017) Medical decision-making in children and adolescents: developmental and neuroscientific aspects. BMC Pediatr 17(1):120

26. Reismann M, Arar M, Hofmann A, Schukfeh N, Ure B (2012) Feasibility of fast-track elements in pediatric surgery. Eur J Pediatr Surg 22(1):40-44

27. Reismann M, Dingemann J, Wolters M, Laupichler B, Suempelmann R, Ure BM (2009) Fast-track concepts in routine pediatric surgery: a prospective study in 436 infants and children. Langenbecks Arch Surg 394(3):529-533

28. Raval MV, Heiss KF (2018) Development of an enhanced recovery protocol for children undergoing gastrointestinal surgery. Curr Opin Pediatr 30(3):399-404

29. Rove KO, Brockel MA, Saltzman AF et al (2018) Prospective study of enhanced recovery after surgery protocol in children undergoing reconstructive operations. J Pediatr Urol 14(3):252.e1-259.e9

30. Thomson K, Pestieau SR, Patel JJ et al (2016) perioperative surgical home in pediatric settings: preliminary results. Anesth Analg 123(5):1193-1200

31. Raval MV, Kwan AB, Travers CD, Heiss KF (2018) Importance of compliance audits for a pediatric complicated appendicitis clinical practice guideline. J Med Syst 42(12):257

32. Yousef Y, Youssef F, Homsy M et al (2017) Standardization of care for pediatric perforated appendicitis improves outcomes. J Pediatr Surg 52(12):1916-1920

33. Snoek KG, Reiss IK, Greenough A et al (2016) Standardized Postnatal Management of Infants with Congenital Diaphragmatic Hernia in Europe: the CDH EURO Consortium Consensus-2015 Update. Neonatology 110(1):66-74

34. Puligandla PS, Skarsgard ED, Canadian Congenital Diaphragmatic Hernia C et al (2018) Diagnosis and management of congenital diaphragmatic hernia: a clinical practice guideline. CMAJ Can Med Assoc journal de l'Association medicale canadienne 190(4):E103-E112

35. Association APS. APSA Statements and Guidelines. (2018).https ://www.eapsa.org/resources/for-professionals/apsa-statements -guidelines/. Accessed 3 Jan 2019

36. Surgeons RCo. Standards for Children's Surgery 2013. (2013) https://www.rcseng.ac.uk/standards-and-research/standards-andguidance/service-standards/childrens-surgery/standards-of-care/. Accessed 3 Jan 2019

Publisher's Note Springer Nature remains neutral with regard to jurisdictional claims in published maps and institutional affiliations. 